\title{
EDITORIAL
}

\section{Allergic rhinitis and rhinosinusitis in primary care: record-keeping, guidelines and implementation}

See linked articles by Hoffmans et al. on pg 64 and Hammersley et al. on pg 71

*Mark L Levy ${ }^{\mathrm{a}, \mathrm{b}}$

a Senior Clinical Research Fellow, Allergy and Respiratory Research Group, Centre for Population Health Sciences: GP Section, University of Edinburgh, Scotland, UK.

b Member of the GINA Executive and GINA Guideline Implementation Group (www.ginasthma.org)

${ }^{*}$ Correspondence:

Dr Mark L Levy,

Allergy \& Respiratory Research Group, Centre for Population Health Sciences:

General Practice Section,

The University of Edinburgh,

Doorway 3, Medical School, Teviot Place, Edinburgh, Scotland, EH8 9AG, UK

Tel: +44 (0)1461 600639

Fax: +44 (0)1461 207819

E-mail: marklevy@animalswild.com

Received 11/2/11
Rhinitis may be allergic (seasonal or non-seasonal), non-allergic, or infective. It may also involve the sinuses, and this is referred to as rhinosinusitis. Rhinosinusitis in turn may be acute or chronic..$^{1-5}$ Allergic rhinitis has been classified by ARIA (Allergic Rhinitis and its Impact on Asthma - www.whiar.org) according to symptom duration (intermittent vs. persistent) and severity (mild vs. moderate/severe), and this has recently been validated in children. ${ }^{4,6}$

Rhinitis and rhinosinusitis are both managed largely in primary care. Both conditions may impact significantly on the lives of our patients - for example, the detrimental effect on children's examination performance due to allergic rhinitis. ${ }^{7}$ As well as the known links between allergic rhinitis and asthma, ${ }^{8}$ accurate diagnosis and evidence-based management are of prime importance for general practitioners (GPS). Two papers in this issue of the $P C R J^{9,10}$ address issues relevant to these conditions in the primary care setting.

The paper by Hammersley et al..$^{9}$ is focused on the computerised record-keeping system in the UK, the way in which patients with seasonal allergic rhinitis (SAR) are coded, and what search methods are available for identifying these patients. They demonstrate very elegantly - through different search strategies - three alternative approaches to identifying these patients, with specificity and sensitivity ranging from 100\%-86\% and $85 \%-17 \%$, respectively. Clearly the solution to the problem of identifying patients through computer searches lies in more rigorous attention to coding detail - ideally through the use of templates which can be used by clinicians when they enter data onto their computer systems. Allergic rhinitis was one of the topics highlighted in the Research Needs Statement from the International Primary Care Respiratory Group (IPCRG) published last year, ${ }^{11}$ and perhaps this matter should be addressed in that context...

The other paper, by Hoffmans et al., ${ }^{10}$ raises further questions - in particular, the implementation of guidelines, and strategies for improving care. In this survey of a Dutch population of GPs regarding the management of rhinosinusitis, the vast majority reported that when consulted by patients presenting with rhinosinusitis they do differentiate into acute and chronic rhinosinusitis. However, the Dutch College of General Practitioners' guideline for this condition does not distinguish between the two in its management advice, perhaps providing evidence of poor adherence to the local strategy?

The term 'evidence-based medicine' has become widely used in practice, and for many its practice has become synonymous with adherence to, or implementation of, guidelines in clinical practice. Of course, some guidelines, position papers, and clinical strategy documents are not truly evidence-based and are unsupported by clinical research findings. However, more recently, guidelines are developed on a firm foundation of scientific evidence. Therefore, the "million dollar question" is whether clinicians are aware of - or indeed, whether they consult and adhere to - guidelines, when managing their patients. As Haines and Jones pointed out years ago, unacceptable delay in the implementation of research findings results in suboptimal care for patients - as exemplified by the 150-year delay in introducing citrus into the diet of sailors to prevent scurvy despite clear and longstanding evidence of its efficacy. ${ }^{12}$ 
In the European position paper, ${ }^{1,5}$ management of rhinosinusitis is to an extent determined by whether patients present with acute or chronic rhinosinusitis - a classification based on whether or not symptoms have persisted for less than (acute) or more than (chronic) 12 weeks. Treatment for both types is determined by the severity of the illness (mild, moderate or severe). Acute rhinosinusitis is one of the commonest reasons for patients consulting their GP, and in most cases antibiotic prescription is not justifiable. ${ }^{1,5}$ The fact that the GPS in the study by Hoffman et al. differentiated this condition into acute and chronic suggests that perhaps they were aware of the European position paper on the subject. However, 1 in 5 still prescribed antibiotics for mild acute rhinosinusitis, thus indicating that they were not following the position paper advice. ${ }^{1,5}$

For many years, we have known about the importance of guideline implementation, 13,14 but many guideline developers fail to include clear strategies for implementation in their guideline statements. Perhaps this is exemplified in the Dutch survey. ${ }^{10}$ To further emphasise the point, the word "implementation" occurs in only one place in the European position paper document (in the Introduction), never to be referred to again in the whole document. ${ }^{5}$ On a more positive note, the Global Initiative for Asthma (GINA www.ginasthma.org) is one of the organisations that is actively developing an implementation strategy. To this end, on World Asthma Day in 2010, the group launched a campaign to reduce asthma hospitalisations worldwide by $50 \%$ over the next five years. This will be achieved through active promotion of implementation strategies to facilitate improved knowledge of the GINA asthma strategy through the use of tools designed specifically for this purpose.

\section{Conflict of interest declaration}

Mark L Levy is the Editor Emeritus of the PCRJ, but was not involved in the editorial review of, nor the decision to publish, this commissioned article.

\section{References}

1. Thomas M, Yawn BP, Price D, et al. EPOS Primary Care Guidelines: European Position Paper on the Primary Care Diagnosis and Management of Rhinosinusitis and Nasal Polyps 2007 - a summary. Prim Care Respir J
2008;17(2):79-89. http://dx.doi.org/10.3132/pcrj.2008.00029

2. Angier E, Willington J, Scadding G, Holmes S, Walker S. Management of allergic and non-allergic rhinitis: A primary care summary of the BSACl guideline. Prim Care Respir J 2010;19(3):217-22. http://dx.doi.org/10.4104/pcrj.2010.00044

3. Scadding GK, Durham SR, Mirakian R, et al. BSACl guidelines for the management of allergic and non-allergic rhinitis. Clin Exp Allergy 2008;38(1):19-42. http://dx.doi.org/http://www3.interscience.wiley.com/cgi-bin/fulltext/119410075/ PDFSTART. http://dx.doi.org/10.1111/j.1365-2222.2007.02888.x

4. Bousquet J, Khaltaev N, Cruz AA, et al. Allergic Rhinitis and its Impact on Asthma (ARIA) 2008 update: In collaboration with the World Health Organization, GA(2)LEN and AllerGen. ARIA update 2008: Die allergische rhinitis und ihr einfluss auf das asthma 2009;32(8):306-19.

5. Fokkens $\mathrm{W}$, Lund $\mathrm{V}$, Mullol J. European position paper on rhinosinusitis and nasal polyps 2007. Rhinology 2007;20:Suppl.1-136.

6. Jauregui I, Davila I, Sastre J, et al. Validation of ARIA (Allergic Rhinitis and its Impact on Asthma) classification in a pediatric population: The PEDRIAL study. Pediatric Allergy and Immunology, in press. 2011. http://dx.doi.org/10.1111/j.1399-3038.2010.01108.x

7. Walker S, Khan-Wasti S, Fletcher M, Cullinan P, Harris J, Sheikh A. Seasonal allergic rhinitis is associated with a detrimental effect on examination performance in United Kingdom teenagers: Case-control study. J Allergy and Clin Immunol 2007; 120(2):381-7. http://dx.doi.org/10.1016/j.jaci.2007.03.034

8. Haughney J, Price D, Kaplan A, et al. Achieving asthma control in practice: Understanding the reasons for poor control. Resp Med 2008;102(12):1681-93. http://dx.doi.org/10.1016/j.rmed.2008.08.003

9. Hammersley V, Flint R, Pinnock H, Sheikh A. Developing and testing search strategies to identify patients with active seasonal allergic rhinitis in general practice. Prim Care Respir j2011;20(1):71-4. http://dx.doi.org/10.4104/pcrj.2010.00086

10. Hoffmans R, Schermer T, van Weel C, Fokkens W. Management of Rhinosinusitis in Dutch general practice. Prim Care Respir J 2011;20(1):64-70. http://dx.doi.org/10.4104/pcrj.2010.00064

11. Pinnock $H$, Thomas $M$, Tsiligianni I, et al. The International Primary Care Respiratory Group (IPCRG) Research Needs Statement 2010. Prim Care Respir J 2010;19(Suppl 1):S1-S20. http://dx.doi.org/10.4104/pcrj.2010.00021

12. Haines A, Jones R. Implementing findings of research. BMJ 1994;308(6942): 1488-92.

13. Royal College of General Practitioners. The development and implementation of clinical guidelines. Report of the clinical guidelines working group. London: RCGP1995.

14. Conroy M, Shannon W. Clinical guidelines: Their implementation in general practice. Br J Gen Pract 1995;45(396):371-5.

\section{Available online at http://www.thepcrj.org}

